\title{
BMJ Open Projecting the prevalence of obesity in South Korea through 2040: a microsimulation modelling approach
}

\author{
Yoon-Sun Jung, ${ }^{1}$ Young-Eun Kim, ${ }^{2}$ Dun-Sol Go, ${ }^{3}$ Seok-Jun Yoon (1) ${ }^{4}$
}

To cite: Jung Y-S, Kim Y-E, Go D-S, et al. Projecting the prevalence of obesity in South Korea through 2040: a microsimulation modelling approach. BMJ Open 2020;10:e037629. doi:10.1136/ bmjopen-2020-037629

- Prepublication history for this paper is available online. To view these files, please visit the journal online (http://dx.doi org/10.1136/bmjopen-2020037629).

Received 10 February 2020 Revised 03 December 2020 Accepted 09 December 2020

Check for updates

(C) Author(s) (or their employer(s)) 2020. Re-use permitted under CC BY-NC. No commercial re-use. See rights and permissions. Published by BMJ.

${ }^{1}$ Department of Public Health, Graduate School, Korea University, Seoul, Korea (the Republic of)

${ }^{2}$ Big Data Department, National Health Insurance Service, Wonju, Korea (the Republic of)

${ }^{3}$ Department of Health Care Policy Research, Korea Institute for Health and Social Affairs, Sejong, Korea (the Republic of) ${ }^{4}$ Department of Preventive Medicine, Korea University College of Medicine, Seoul, Korea (the Republic of)

Correspondence to

Dr Seok-Jun Yoon;

yoonsj02@korea.ac.kr

\section{ABSTRACT}

Objective To project the prevalence of obesity in 2040 among individuals 19 years and older in South Korea. Design, setting, and participants Using the 'Population Health Model-body mass index' (BMI) microsimulation model, the prevalence of obesity in Korean adults 19 years and older was projected until 2040. The model integrated individual survey data from the Korea Health Panel Survey of 2011 and 2012, population statistics based on resident registration, population projections and complete life tables categorised by sex and age. Birth rate, life expectancy and international migration were based on a medium growth scenario. The base population of Korean adults in 2012, devised through data aggregation, was 39842730 . The prediction equations were formulated using $\mathrm{BMl}$ as the dependent variable; the individual's sex, age, smoking status, physical activity and preceding year's BMI were used as predictive factors.

Outcome measure BMI categorised by sex.

Results The median BMI for Korean adults in 2040 was expected to be $23.55 \mathrm{~kg} / \mathrm{m}^{2}$ (23.97 and $23.17 \mathrm{~kg} / \mathrm{m}^{2}$ for men and women, respectively). According to the Korean BMI classification, $70.05 \%$ of all adults were expected to be 'preobese' (ie, have BMls 23-24.9 kg/m²) by 2040 ( $81.23 \%$ of men and $59.07 \%$ of women) and $24.88 \%$ to be 'normal'.

Conclusions We explored the possibility of applying and expanding on the concept of microsimulation in the field of healthcare by combining data sources available in Korea and found that more than half of the adults in this study population will be preobese, and the proportions of 'obesity' and 'normal' will decrease compared with those in 2012. The results of our study will aid in devising healthy strategies and spreading public awareness for preventing this condition.

\section{BACKGROUND}

The prevalence of overweight and obesity has increased markedly over the past three decades, and concerns about health risks associated with obesity have become almost universal. ${ }^{1}$ The increasing rate of obesity is a growing public health concern not only in Western countries but also in South Korea. ${ }^{2}$ From the 1990s to the beginning of the new millennium, the prevalence of adult and child obesity has increased rapidly and continues

\section{Strengths and limitations of this study}

To the best of our knowledge, this is the first study to use a microsimulation model to predict future obesity prevalence in Korea considering the change in population structure (macro-level) as well as individual health behaviour components (micro-level).

- The results of our study will be beneficial in suggesting additional and wider ranging goals for obesity prevention, by taking into consideration the influence of sex and age in the formulation of the 'National Health Plan'.

- Although a representative data source was used in this study, the prevalence of obesity may be underestimated because it is based on a self-reported body mass index value.

- This study uses a microsimulation model developed abroad, and hence, may not reflect the domestic situations accurately.

- Another limitation is that we assumed the attributes of 19-year-old individuals to remain similar each year.

to rise steadily in parallel with rapid social and economic development. ${ }^{3}$

Obesity, a major public health problem and a factor in the development of many chronic diseases, constitutes a strain on individuals and health systems worldwide. The associated disorders of obesity include diabetes, hypertension, dyslipidaemia, heart disease, stroke, sleep apnoea, early death and cancer. ${ }^{4-8}$ Moreover, obesity among older people increases the risk of knee osteoarthritis ${ }^{9}$ and reduces functional capacity and quality of life..$^{10-13}$ The prevalence of these conditions rises in proportion to the increase in obesity ${ }^{14-17}$ and is associated with increased economic costs for both individuals and the society at large. ${ }^{18}$ A study using the National Health Insurance Service data in Korea found that the socioeconomic cost of obesity in 2016 was approximately US $\$ 9665.32$ million. ${ }^{19}$

Meanwhile, with respect to worldwide comparisons, whether cut-off points for overweight and obesity should be lower for 
Asians than for another ethnic groups remains debatable. ${ }^{20}$ WHO has proposed body mass indices (BMIs) of $18.5-22.9,23-24.9,25-29.9$ and $\geq 30 \mathrm{~kg} / \mathrm{m}^{2}$ as optimal, overweight, moderate and severe obesity for Asians, respectively. ${ }^{21}$ The Korean Society of Obesity, which was established to improve obesity management through research and education, revised its clinical practical guidelines for the prevention and treatment of obesity in 2018. The new guidelines renamed the 'overweight' category to 'preobese' and divided obesity into three categories, to highlight the risk of obesity, instead of promoting the term 'overweight'. The most recent guideline is based in part on data of 84690131 Korean adults extracted from the Korean National Health Insurance Service Health Check-up Database between 2006 and 2015. By including the entire population registered in the National Health Insurance Service Database, they calculated the first and second cut-off points corresponding to the increased risk of any of the three accompanying diseases (type 2 diabetes, hypertension and dyslipidaemia). The first (23 $\left.\mathrm{kg} / \mathrm{m}^{2}\right)$ and second $\left(25 \mathrm{~kg} / \mathrm{m}^{2}\right)$ cut-off BMI levels suggest the necessity of obesity criteria that accurately reflect the risk of chronic disease among Koreans. ${ }^{22} 23$

Although numerous investigators in other countries have attempted to predict the future prevalence of obesity, only one such study by Inkyung Baik was recently performed in South Korea. ${ }^{2}$ More recent trends still need to be investigated through predictive studies, and the accurate prediction of obesity prevalence remains an important public health-related goal in the country. To efficiently establish and execute an effective healthcare policy, which would require a large budget, it is necessary to select future targets for policy interventions (such as high-risk groups) to predict healthcare needs and prevent budget waste.

Past prediction models incorporated a country's entire population; as such, macroscopic inferences based on average projections for the future society were generalised. However, when establishing a healthcare policy, it is necessary to predict the future burden of disease and medical needs of the entire population based on a real-world understanding of individual-level factors that are influenced by policies or institutions. Individuals are independent entities with different characteristics and needs, and health-related projections can be modelled to reflect these individual characteristics, including health risk factors. ${ }^{24}$ In this regard, we aimed to predict the prevalence of obesity in Korea by using microsimulation, which is optimal for considering individual properties.

Microsimulation, a modelling technique, typically uses individual microunits, each with its own set of properties, to simulate downstream events based on the probability of transition between predefined states and their changes over time. When used in medicine, microsimulation can be particularly powerful because it preserves the patterns of previous behaviours and conditions, and allows for a clearer representation and understanding of how various processes affect the total outcome of the population over time. ${ }^{25}$ Given macro effects such as changes in population structures in the forecasting model, microsimulation is very useful as it can estimate both disease burdens and medical needs across the country. ${ }^{24}$ Microsimulation modelling is particularly useful for studying BMI trends because it can simultaneously explain population dynamics such as ageing and mortality. ${ }^{26}$ However, while microsimulation models have been steadily evolving across health-related and economy-related fields in many European countries, ${ }^{27}$ they are yet to be actively utilised in South Korea (especially for healthcare).

Obesity prevalence and trend estimates provide important information for research, policy and intervention. ${ }^{28}$ Because health forecasting predicts disease episodes and portends future events, it facilitates healthcare strategies by promoting the setting of goals to reduce obesity, establish health promotion interventions and optimise resource allocation. ${ }^{29}$ Obesity trends may also be used to urge governments to implement preventative approaches for reducing obesity. ${ }^{30}$ Based on the above findings, we performed this study to project the future trends in obesity prevalence in South Korea up to the year 2040 .

\section{METHODS}

\section{Model}

We used the Population Health Model (POHEM)-BMI ${ }^{26}$ to estimate the prevalence of obesity among adults 19 years and older in South Korea from 2012 to 2040. In brief, POHEM is a time-continuous, population-based, dynamic microsimulation model with individual underlying units of analysis used worldwide. Dynamic microsimulation, in the context of social science and population health, is a simulation of individuals (ie, micro-level) and their behaviours, statuses and actions (dynamics) over time. ${ }^{31}$ These are modelled as desired using multiple sources of empirical data, including cross-sectional surveys, administrative databases, vital statistics and census data. ${ }^{32}$

Through dynamic simulation, POHEM creates a population and ages it, one person at a time, until death. ${ }^{33}$ The model dynamically simulates an individual's disease state, risk factors and health determinants to describe and plan health outcomes. ${ }^{32}$ POHEM is accessible because it wants the general process to be constant across the country's population, with the exception of variables unique to each country, such as marriage and mortality. The POHEM models include cardiovascular disease, various cancers, osteoarthritis, physical activity and neurological events. The model used in this study was the POHEM-BMI; the performance of each prediction step is shown in figure 1.

\section{Base population}

To create the base population for the POHEM-BMI model, we used the 2011-2012 Korea Health Panel survey $^{34}$ and the resident registration-based population statistics. ${ }^{35}$ The base population for POHEM-BMI ( $\mathrm{n}=39$ 842 730), reflected the Korean population. Each Korean 
Figure 1 Summary of data sources and methods used to generate and validate projections of distribution of BMI categories in South Korea, 2012-2040

\section{Step1: \\ Generate an initial Korean population}

\section{Step2:}

Annual update

Data

sources

Update

method

Step3:

Validate and

Calibrate model

Step4:

Projection
Initialize a predictive model by generating synthetic cohort of actual Korean population aged 19 years and older in 2012 ( $n=39,842,730$ ) using Korea Health Panel Survey $(n=11,501)$. BMI, pre-BMI, smoking rate, and physical activity rate were imputed from information in the Korea Health Panel Survey.

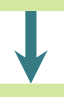

Each year to 2040, update synthetic cohort for demographic changes and BMI

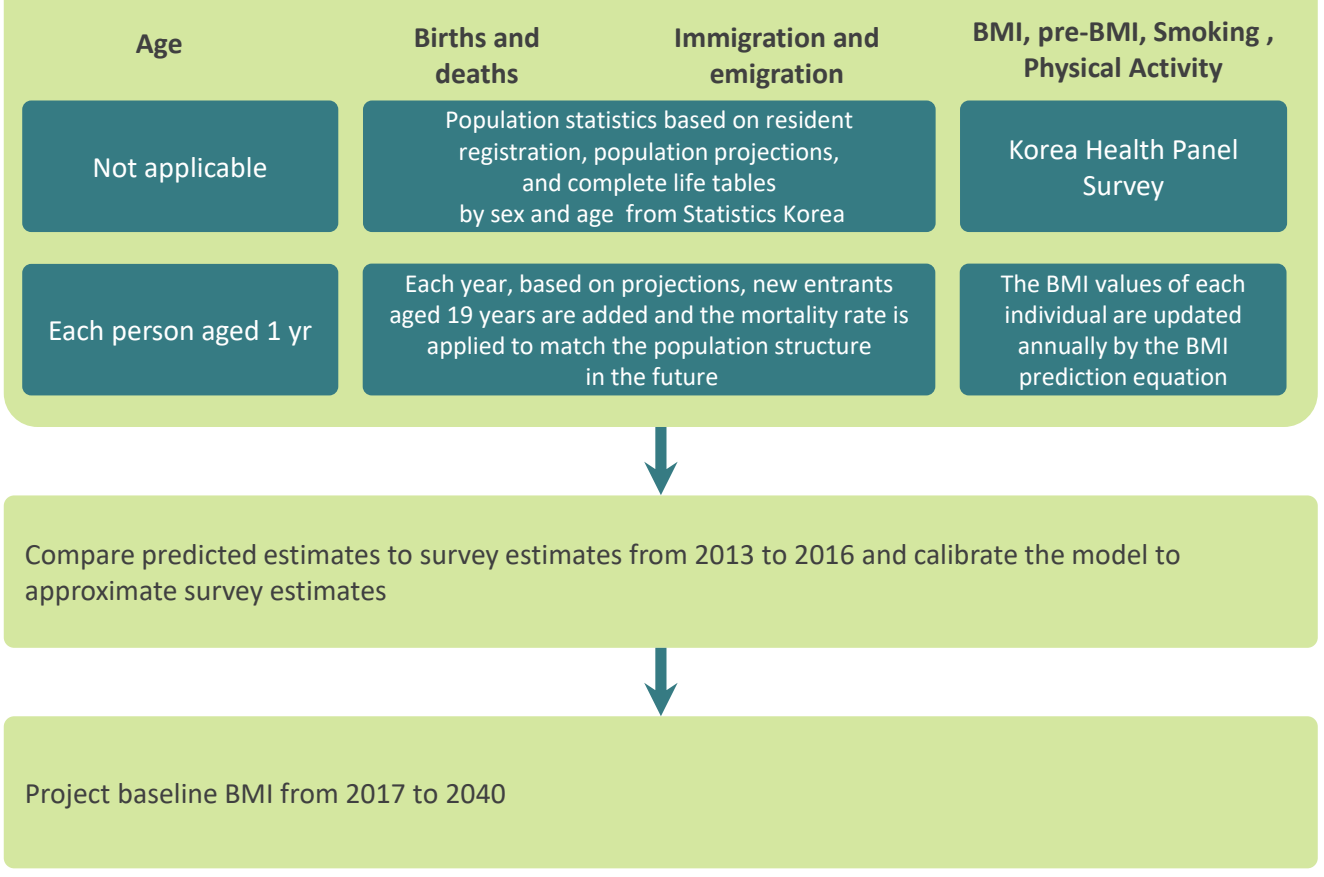

Figure 1 Summary of the data sources and methods used to generate and validate the projections of the distribution of BMI categories in South Korea, 2012-2040. BMI, body mass index.

respondent 19 years of age and older $(n=11501)$ in 2012 was replicated using their survey-recorded weights to generate a simulated cohort of approximately 39842730 individuals. Korea Health Panel survey data are nationally representative, and incorporate health status, chronic diseases, health risk behaviours and sociodemographic characteristics. Among them, we extracted sex, age, current smoking status, physical activity and the previous and current years' BMI values; these variables were required for the predictive equation. We then used a multiple linear regression model to estimate the BMI value using the extracted independent variables as predictors. The POHEM-BMI model is autoregressive and includes previous BMI values as the main explanatory variable. ${ }^{26}$ We matched the composition of the variables considered as covariates in the POHEM-BMI model. We did not match the operational definition of the variables because we applied the Korea Health Panel Survey data (not the survey data obtained in Canada where the POHEM model was developed). The definitions of the variables in this study are consistent with the definitions of the indicators in the Korea Health Statistics. ${ }^{36} \mathrm{~A}$ current smoker was an individual who reported smoking 'every day' or 'sometimes'. Practising physical activity was defined as performing either intense physical activity for at least 10 continuous minutes a day, 20 min total per day, 3 days a week during the preceding week or moderate physical activity for at least $30 \mathrm{~min}$ a day, 5 days a week during the preceding week. Height and weight, which are components of BMI, were based on self-reported data.

\section{Simulation: annual updates and risk transition}

The study population was updated by ageing each person by 1 year and changing the total population size based on population statistics, population projections and complete life tables categorised by sex and age from the Korean Statistics. For population projections, we assumed a medium growth scenario in terms of birth rate, life expectancy and international migration. Each person's BMI was updated annually by applying a predictive equation that incorporates individual's own characteristics. The transition probability for each stochastic characteristic was calculated based on a generalised linear model. 
We assumed that the current individual behavioural patterns persisted, and no new factors arose to prevent obesity, like in the original POHEM-BMI. We also assumed that the attributes of 19-year-old individuals, which were entered annually, remained similar each year. Therefore, in this model, since each individual's smoking status and physical activity in the initial population remained the same until 2040, the model predicted the BMI when the adult smoking and physical activity rates in the initial year (2012) persisted until 2040.

\section{Model validation and calibration}

In order to establish the validity of the prediction model, we adjusted the model by comparing the 2013-2016 median BMIs projected from the model with the 20132016 Korea Health Panel Survey median BMI estimates. We compared the median BMI values for each sex and age group from 2013 to 2016, and accepted a difference between the median BMI values in the prediction model and in the Korea Health Panel Survey to less than 5\% by setting the calibration cut-off point to $5 \%$. Finally, we adjusted the demographics of the 2040 population so that the predictions were within the $5 \%$ margin of error.

\section{Projection}

The model, validated through calibration, projected the BMI of each person from 2017 to 2040 . Based on the demographic characteristics, the projections were then aggregated by year for each of the predefined subgroups. The various trends observed in the Korean population data were used to generate algorithms that were applied to future projections.

\section{Model outputs}

The BMI distributions were calculated overall and by sex. Individuals with a BMI $\geq 25 \mathrm{~kg} / \mathrm{m}^{2}$ were regarded as obese according to the Guidelines for the Management of Obesity in Korea, which is not the internationally accepted standard (table 1). All analyses in this study were performed using STATA V.13 (StataCorp).

\section{Patient and public involvement}

No patient involved.

\begin{tabular}{ll}
\hline Table 1 BMI classification of South Korea \\
\hline Classification & BMI $\left(\mathbf{k g} / \mathbf{m}^{2}\right)$ \\
\hline Underweight & $<18.5$ \\
\hline Normal & $18.5-22.9$ \\
\hline Preobese & $23-24.9$ \\
Obese class I & $25-29.9$ \\
Obese class II & $30-34.9$ \\
\hline Obese class III & $\geq 35$
\end{tabular}

BMI, body mass index.

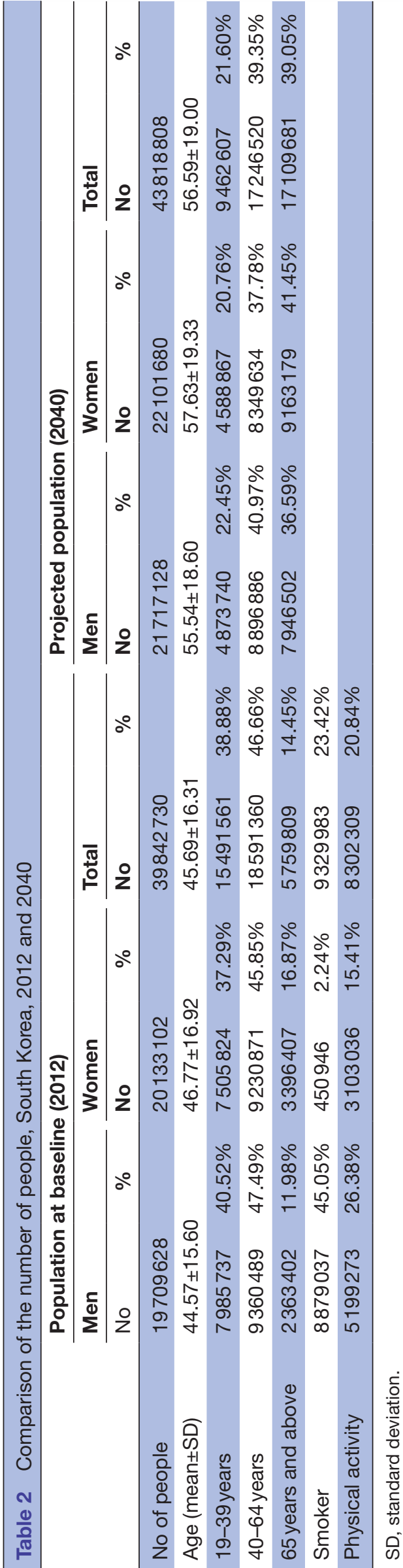




\section{RESULTS}

We compared the total number of the individuals and their characteristics in the initial 2012 population to those in the projected 2040 population (table 2). There were 39842730 adults who were 19 years of age or older in 2012 and 43818808 in 2040. The male: female ratio was nearly 1:1 in both 2012 and 2040. Rapid ageing of the Korean population was clearly observed when comparing the two populations. The mean age of adults was expected to increase by 10.9 years (from 45.69 years in 2012 to 56.59 years in 2040 (from 44.57 to 55.54 years among men and 46.77 to 57.63 years among women)). In 2012, the proportion of young people (those in the 19-39 and 40-64year age groups combined) accounted for approximately $85.54 \%$ of the adult population, while the proportion of individuals aged 65 years and older was relatively low at approximately $14 \%$. However, the age group structure in South Korea 28 years later (2040) is predicted to be quite different, as the proportion of individuals 19-64years (ie, the working age population) was only $60.95 \%$ of the adult population, while the proportion of the elderly population ( $\geq 65$ years) was estimated to be almost $40 \%$ of the total adult population. As of 2012, men and women smoking rates were $45.05 \%$ and $2.24 \%$, respectively, and physical activity rates were $15.41 \%$ and $20.84 \%$, respectively. In this study, only the BMI was updated annually by the predictive equation, so the adult smoking rate and physical activity rate in 2040 are the same as in the initial 2012 population.

The model was well calibrated to establish the validity. The difference in median BMI between that estimated from the 2013 and 2016 Korea Health Panel survey and that predicted by the 2013 and 2016 model was within the
$5 \%$ range. Additionally, when compared with the population structure for 2040 (the final year) as predicted by Statistics Korea, the total population, gender-specific and age-specific ratio in the prediction model were similar.

Figure 2 shows the median BMI of the adult population from 2012 when the initial population was generated to 2040, the final projected year. Each median BMI value from 2013 to 2016 was estimated from the Korea Health Panel survey, and the median BMI from 2017 to 2040 is the predicted value determined by the model. The median BMI for the entire adult population is predicted to increase very slightly from $23.23 \mathrm{~kg} / \mathrm{m}^{2}$ in 2018 to $23.53 \mathrm{~kg} / \mathrm{m}^{2}$ in 2036 and is expected to remain steady thereafter. The predicted median BMI trends are similar for men; the median BMI in adult men was projected to increase only slightly, from $23.74 \mathrm{~kg} / \mathrm{m}^{2}$ in 2018 to $23.95 \mathrm{~kg} / \mathrm{m}^{2}$ in 2036 and then almost plateau thereafter. However, women were expected to experience a relatively steep rise compared with that of men; the median BMI in adult women was projected to increase from $22.66 \mathrm{~kg} /$ $\mathrm{m}^{2}$ in 2018 to $23.17 \mathrm{~kg} / \mathrm{m}^{2}$ in 2040 . The model in this study, used to predict the BMI of the population, did not include any uncertainty parameters for the estimates.

The BMI distributions for men and women from 2012 to 2040 are shown in figure 3 . There was no significant difference between the median BMIs in 2012 and 2040, but the results according to the BMI classifications showed large changes. The proportions of 'preobese' individuals in both sexes are predicted to increase dramatically over time, while the proportions of individuals who are classified as 'normal' and 'obese' will gradually decrease. As of $2025,52.35 \%$ of all male adults were expected to be preobese, with that proportion expected to be close to $81.23 \%$

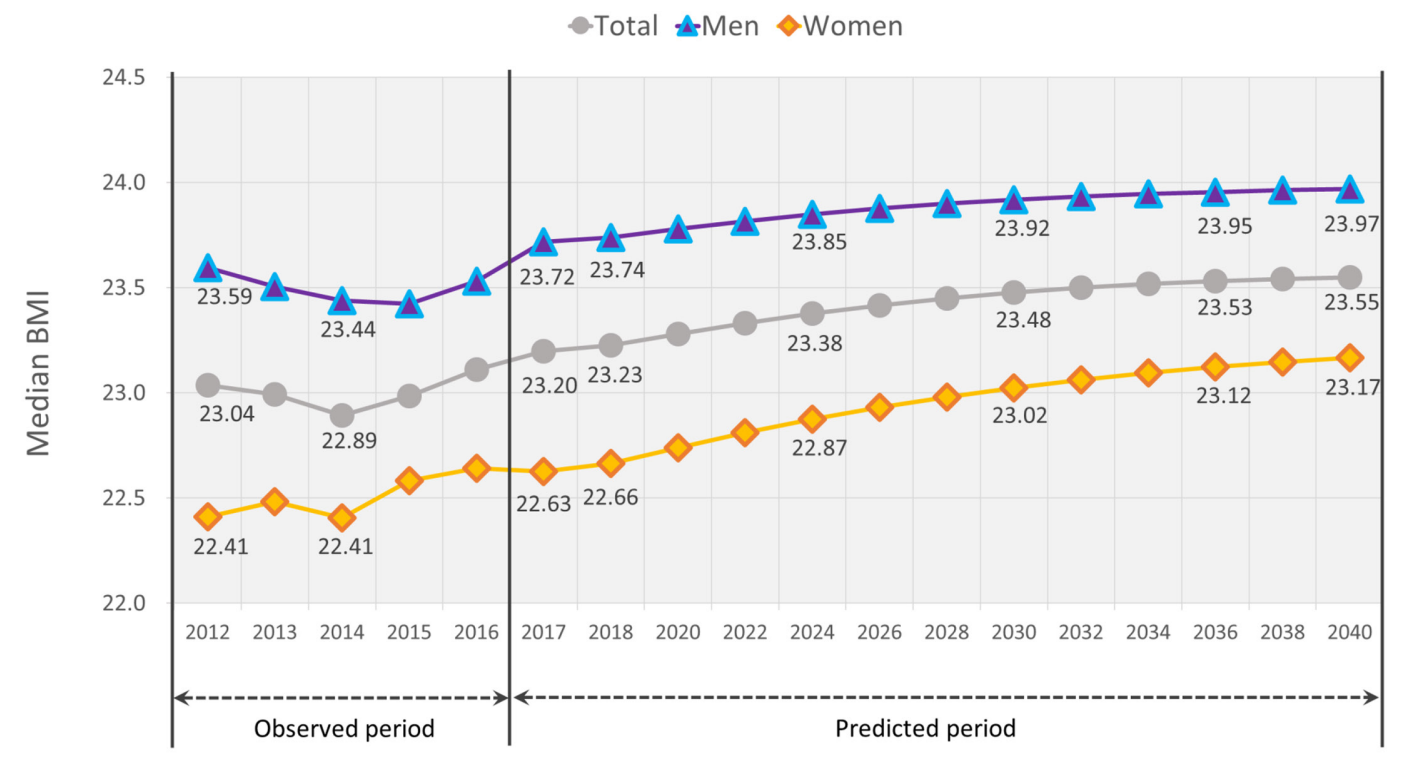

Year

Figure 2 Population Health Model projections of median BMI in South Korea, 2012-2040. BMI, body mass index. 
A

Enderweight E Normal |

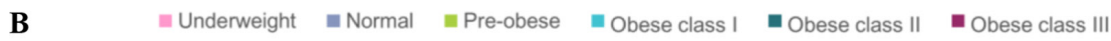

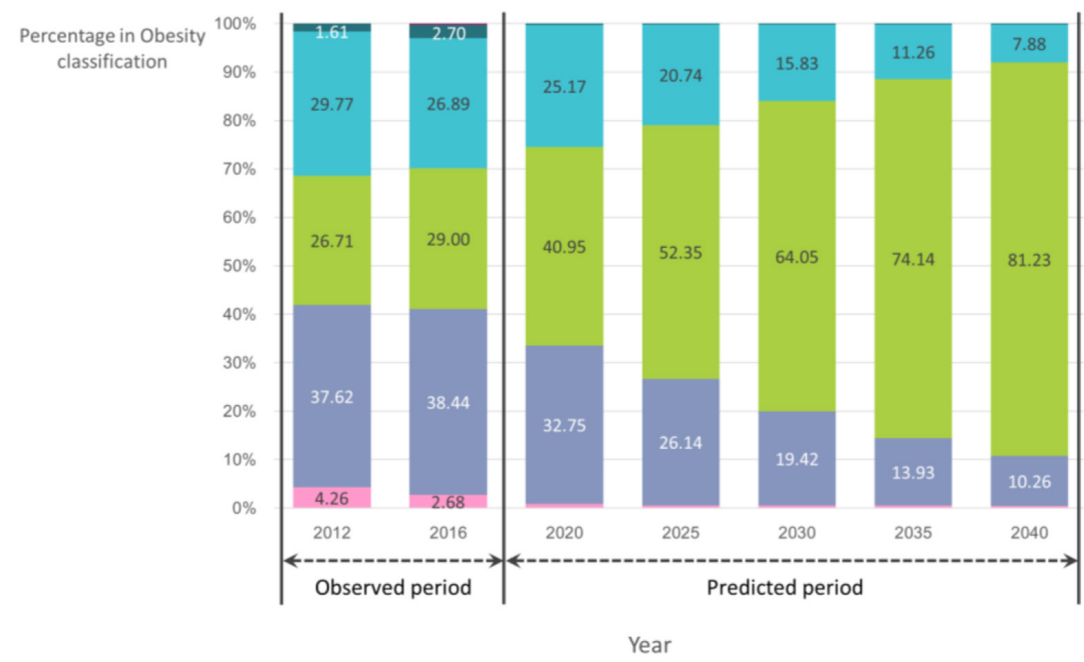

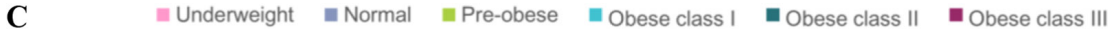

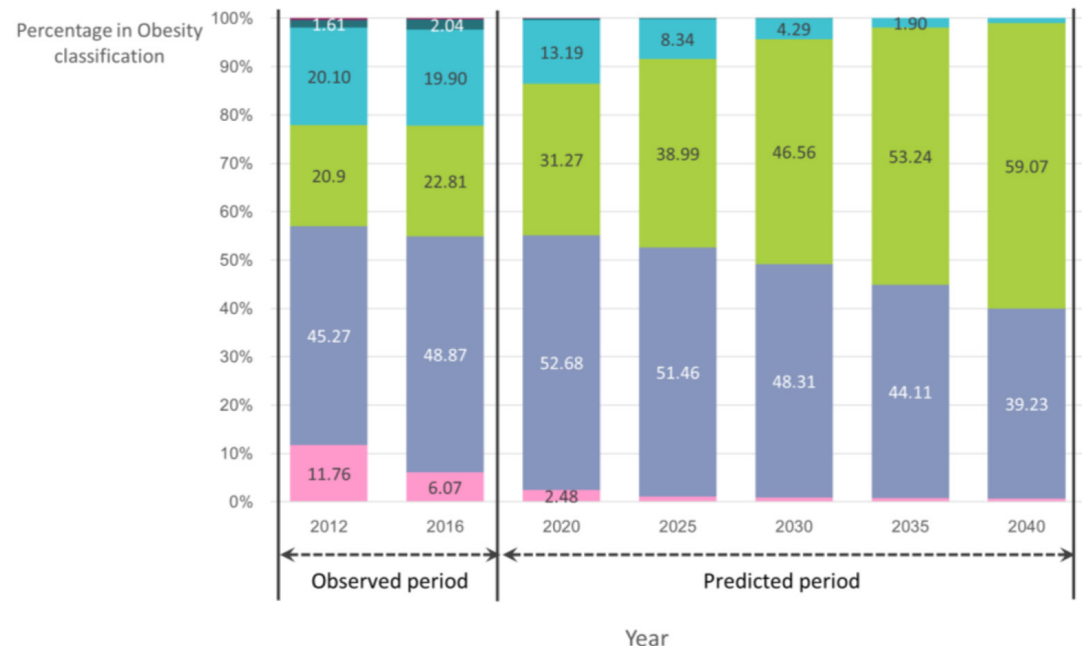

Figure 3 (A) Projection of the distribution of BMI, adults aged 19years and older, South Korea, 2012-2040. (B) Projection of the distribution of BMI, men aged 19 years and older, South Korea, 2012-2040. (C) Projection of the distribution of BMI, women aged 19 years and older, South Korea, 2012-2040. BMI, body mass index. 
Table 3 Comparison of the number of people according to the BMI classification by age group, South Korea, 2012 and 2040

Population at baseline (2012)

Projected population (2040)

\begin{tabular}{|c|c|c|c|c|c|c|}
\hline & \multicolumn{3}{|c|}{ Populatıon at baseline (2012) } & \multicolumn{3}{|c|}{ Projected population (2040) } \\
\hline & 19-39 years & $40-64$ years & 65 years & 19-39years & 40-64 years & 65 years \\
\hline No of people & 15491561 & 18591360 & 5759809 & 9462607 & 17246520 & 17109681 \\
\hline BMI (median) & 22.37 & 23.52 & 23.02 & 23.07 & 23.64 & 23.58 \\
\hline \multicolumn{7}{|c|}{ Distribution of people by BMI classification } \\
\hline Underweight \% & 11.76 & 5.10 & 7.60 & 2.66 & 0.00 & 0.00 \\
\hline Normal \% & 45.66 & 37.81 & 42.12 & 45.68 & 19.89 & 18.40 \\
\hline Preobese \% & 20.36 & 26.51 & 24.10 & 39.59 & 76.60 & 80.31 \\
\hline Obese class I \% & 20.67 & 28.40 & 24.85 & 11.70 & 3.51 & 1.29 \\
\hline Obese class II \% & 1.51 & 1.79 & 1.30 & 0.36 & 0.00 & 0.00 \\
\hline Obese class III \% & 0.03 & 0.38 & 0.02 & 0.02 & 0.00 & 0.00 \\
\hline
\end{tabular}

BMI, body mass index.

by 2040 . Moreover, $53.24 \%$ of all women were expected to be 'preobese' by 2035 , with the proportion rising to almost $59.07 \%$ by 2040 .

According to the BMI classification by age group, in South Korea, in 2012 , about $20.36 \%$ of the population aged 19-39 were 'preobese', but in 2040, it increased to $39.59 \%$, almost double. The proportion of the 'normal' population was almost the same in 2012 and 2040, and the 'obese class I' decreased by nearly half. However, in the population aged 40-64 and over 65 , the proportion of 'preobese' increased almost three times in 2040 compared with that in 2012, and the proportion of 'normal' decreased to less than 20\% (table 3).

\section{DISCUSSION}

The purpose of this study was to predict the prevalence of obesity in South Korea in the year 2040 using a microsimulation model. In this study, we strove to predict future adult obesity rates in South Korea using the POHEM-BMI, which was developed by Statistics Canada. Summarising the predicted results, the median BMI of South Korea's adult population aged 19years and older was expected to be 23.55 in 2040, while the percentage of 'preobese' individuals was expected to increase over time. While it is encouraging that the proportion of 'obese' people (ie, those with BMIs $\geq 25 \mathrm{~kg} / \mathrm{m}^{2}$ ) in 2040 is predicted to be much lower than that in 2012, it is discouraging that the proportion of 'normal' individuals is also markedly lower. Most notably, the preobesity rate is predicted to rise dramatically. In addition to the sex and age variables, our model includes only smoking and physical activity as health-related behaviours. It was assumed that the status of these health risk factors remain consistent from the initial population period to the final projected year of 2040; hence, our results showed that maintaining smoking and physical activity rates in 2012 among adults will lead to a sharp increase in the 'preobese' population by 2040 .

To the best of our knowledge, the only other study that predicted future obesity rates among South Korean adults was the investigation by Baik. ${ }^{2}$ That study explored factors affecting adult as well as abdominal obesity, and constructed forecasting models to predict obesity prevalence rates in 2020 and 2030 using the Korea National Health and Nutritional Examination Survey (KNHANES). The prevalence rates of obesity among men and women in that study were predicted to be $47 \%$ and $32 \%$, respectively, in 2020 and $62 \%$ and $37 \%$, respectively, in 2030; these data were inconsistent with our results. The differences in prediction results appeared to be caused by the different secondary sources and prediction models in the two studies. First, in Baik's study, a prediction model was constructed by applying a linear regression model and an autoregressive integrated moving average model using the KNHANES data. The dependent variable in the prediction model was BMI, and the independent variables included the survey year, age, marital status, job status, income status, smoking, alcohol consumption, sleep duration, psychological factors, dietary intake and fertility rate. In contrast, in this study, the Korea Health Panel data was used as the data source, and BMI was predicted by performing microsimulation with sex, age, smoking, physical activity, and previous years' BMIs as independent variables. Therefore, the method of measurement of the dependent variable, BMI differs between the studies; unlike the KNHANES, which contains body-measured height and weight information, the Korea Health Panel (although this is a representative data source) generates data based on self-reported by respondents, which may underestimate obesity. Inevitably, the obesity rate in the initial population according to the KNHANES tended to be higher; as such, a higher initial prevalence rate would lead to a higher projection. ${ }^{37}$

We also tried to compare the results from this study with the predicted estimate by country, but few studies have empirically predicted the prevalence of obesity in the future using simulation models. One study compiled nationally representative data from various sources and predicted the future prevalence of overweight and obesity in Indian adults aged 20-69 years will reach $30.5 \%$ and $9.5 \%$ among men, $27.4 \%$ and $13.9 \%$ among 
women, respectively, by $2040 .{ }^{38}$ According to a study that estimated the prevalence of obesity in the future through regression modelling, $42 \%$ of Americans were expected to be obese by $2030 .{ }^{39}$ Similarly, a study that predicted the prevalence of obesity in Australian adults by 2025 using a multiple linear regression model predicted that $83 \%$ of male adults over the age of $20 \%$ and $75 \%$ of female adults would be overweight or obese. ${ }^{40}$ In all three countries, India, the USA and Australia, overweight and obesity were defined according to the classifications defined by $\mathrm{WHO}$, and much higher values were found than those in Korea. We also compared our results to those predicted in Canada using the same model, and $59 \%$ of the adult Canadian population was predicted to be 'overweight or obese' by 2030 .

This study defined obesity by applying the BMI classification system according to 2018 Korean Society for the Study of Obesity guideline for the management of obesity in Korea. It would be appropriate to use international standards for comparison; however, it is necessary to reflect the situation of individual countries in the management of obesity for the purpose of preventing and managing chronic diseases. Therefore, rather than emphasising the BMI classification criteria, more research is needed to determine the BMI values that can significantly predict the occurrence of chronic diseases. In other words, it is necessary to continuously accumulate sufficient epidemiological evidence for the relationship between the BMI and the actual risk of disease and death for Koreans, and based on such evidence, efforts to establish appropriate diagnostic and medical standards for Koreans are needed. In particular, the relationship is likely to vary by age and sex; hence, it should be considered too. Here, the obesity standard has been applied collectively regardless of sex and age. However, in order to deviate from a uniform approach to obesity, gender-based and agebased approaches are needed, considering the changes in hormones and body composition.

Because health management policies including obesity management require a large budget, it is most important to establish cost-effective policies. The results from this study made it possible to determine the obese high-risk group by sex and age group, and to estimate medical needs. As it is necessary to apply obesity standards differently according to sex and age group, it is difficult to set the 'National Health Plan' ${ }^{41}$ goals. This plan needs to suggest additional, wider ranging goals considering the characteristics of each sex and age group, rather than presenting goals for obesity prevalence among adult men and women. In this case, the goal should be presented at an achievable level in consideration of future prediction patterns. Finally, systematic public health interventions, which are tailored to individual characteristics need to be established.

Findings from this study should be interpreted with consideration to several limitations. First, since a microsimulation model for predicting obesity prevalence has not been developed in South Korea, we adapted the model developed by Statistics Canada, and this may not fit our domestic situation. If the BMI predictors are suitable for our domestic situation, that is, if variables that are important for predicting BMI of Koreans are constructed through empirical analysis or literature review, the composition of the covariates may be different from that of the existing POHEM-BMI model. However, in this study, since we explored the possibility of a domestic application of the model and carefully adapted the existing model, the process of constructing a prediction equation was omitted. In the future, research to develop a new model of microsimulation in the field of healthcare for domestic conditions will be very valuable. In this process, it is necessary to consider practical suitability and efficiency in selecting basic data, module-specific behavioural equations and variables for use in the model. Second, we had limited data sources. The prevalence of obesity calculated in this study is different from that of the Korea Health Statistics using the KNHANES, and as of 2011, the prevalence of adult obesity in the Korea Health Statistics was $8.2 \%$ higher than that of the Korea Health Panel Survey. ${ }^{42}$ Although the method of measuring BMI in KNHANES is more accurate, in the POHEM-BMI model used in this study, the BMI of the previous year was regarded as the main explanatory variable, and therefore, the Korea Health panel data that followed-up the same participants once a year was inevitably used. In addition, the original POHEM-BMI model includes the process of converting self-reported BMI into a measured BMI, but we omitted this due to limitations of the data source. Third, we assumed that the attributes of 19-year-old individuals entered each year remain at a similar level each year. This means that the individual attributes of 19-year-old adults are the same for 29 years from 2012 to 2040; thus, it can be considered somewhat less realistic. In future studies, it is expected that more meaningful and realistic results will be derived if the model is constructed by reflecting the trend of changes in the attributes of the 19-year-old population and updating it according to the year.

Nevertheless, our study is the first to examine the possibility of using microsimulation to predict future BMI medians in South Korea. Additionally, the BMI of the future adult population was predicted after considering the change in population structure at the macro-level as well as individual health behaviour components at the micro-level.

\section{CONCLUSION}

The key finding of this study is that by $2040,70.05 \%$ of Korean adults are predicted to be preobese. Using data sources available in Korea, the possibility of applying and expanding on the concept of microsimulation was explored. In future studies, a model suitable for South Korea needs to be developed, and the effectiveness of specific health policies ought to be assessed by applying various relevant scenarios to the basic forecasting model.

Correction notice This article has been corrected since it first published. The provenance and peer review statement has been included. 
Contributors Y-SJ (the first author) designed the study, analysed and interpreted the data and wrote the paper. Y-EK participated in the statistical analysis. D-SG provided assistance in the interpretation of the data and preparation of the manuscript. S-JY (the corresponding author) directed this study. All authors read and approved the final version of the manuscript.

Funding This work was supported by the National Research Foundation of Korea (NRF) grant funded by the Korea government (Ministry of Science and ICT) (No. 2017R1A2B4005876)

Disclaimer The funding agency had no role in the study design, analysis and interpretation of the data, or the preparation of the manuscript.

Competing interests None declared.

Patient and public involvement Patients and/or the public were not involved in the design, or conduct, or reporting, or dissemination plans of this research.

\section{Patient consent for publication Not required}

Ethics approval This study used publicly available data of Korea Health Panel Survey 2011-2012 from the Korea Institute for Health and Social Affairs and the National Health Insurance, population statistics based on resident registration, population projections, complete life tables and future mortality rates from Statistics Korea. The dataset does not contain any identifiable personal information. Ethical approval was given by the Institutional Review Board of Korea University, Seoul, Korea (IRB No. KUIRB-2020-0018-01).

Provenance and peer review Not commissioned; externally peer reviewed.

Data availability statement Data are available in a public, open access repository. The Korea Health Panel Survey data used in this article is available in https://www. khp.re.kr:444/eng/main.do. Detailed information on the survey design and data characteristics are provided at https://www.khp.re.kr:444/eng/survey/sampling.do. Population statistics, population projections, and complete life tables are available from http://kosis.kr/eng/.

Open access This is an open access article distributed in accordance with the Creative Commons Attribution Non Commercial (CC BY-NC 4.0) license, which permits others to distribute, remix, adapt, build upon this work non-commercially, and license their derivative works on different terms, provided the original work is properly cited, appropriate credit is given, any changes made indicated, and the use is non-commercial. See: http://creativecommons.org/licenses/by-nc/4.0/.

ORCID iD

Seok-Jun Yoon http://orcid.org/0000-0003-3297-0071

\section{REFERENCES}

$1 \mathrm{Ng} \mathrm{M}$, Fleming T, Robinson M, et al. Global, regional, and national prevalence of overweight and obesity in children and adults during 1980-2013: a systematic analysis for the global burden of disease study 2013. Lancet $2014 ; 384: 766-81$

2 Baik I. Forecasting obesity prevalence in Korean adults for the years 2020 and 2030 by the analysis of contributing factors. Nutr Res Pract 2018;12:251-7

3 Kim DM, Ahn CW, Nam SY. Prevalence of obesity in Korea. Obes Rev 2005;6:117-21.

4 Okosun IS, Chandra KM, Choi S, et al. Hypertension and type 2 diabetes comorbidity in adults in the United States: risk of overall and regional adiposity. Obes Res 2001;9:1-9.

5 Krauss RM, Winston M, Fletcher BJ, et al. Obesity: impact on cardiovascular disease. Circulation 1998;98:1472-6.

6 Chin K, Ohi M. Obesity and obstructive sleep apnea syndrome. Intern Med 1999;38:200-2.

7 Wallström P, Bjartell A, Gullberg B, et al. A prospective Swedish study on body size, body composition, diabetes, and prostate cancer risk. Br J Cancer 2009;100:1799-805.

8 Guh DP, Zhang W, Bansback N, et al. The incidence of comorbidities related to obesity and overweight: a systematic review and meta-analysis. BMC Public Health 2009;9:88.

9 Coggon D, Reading I, Croft P, et al. Knee osteoarthritis and obesity. Int J Obes Relat Metab Disord 2001;25:622-7.

10 Stenholm S, Rantanen T, Alanen E, et al. Obesity history as a predictor of walking limitation at old age. Obesity 2007;15:929-38.

11 Alley DE, Chang VW. The changing relationship of obesity and disability, 1988-2004. JAMA 2007;298:2020-7.

12 Larsson U, Karlsson J, Sullivan M. Impact of overweight and obesity on health-related quality of life--a Swedish population study. Int J Obes Relat Metab Disord 2002;26:417-24.
13 Zaninotto P, Pierce M, Breeze E, et al. BMI and waist circumference as predictors of well-being in older adults: findings from the English longitudinal study of ageing. Obesity 2010;18:1981-7.

14 Emerging Risk Factors Collaboration, Wormser D, Kaptoge S, et al. Separate and combined associations of body-mass index and abdominal adiposity with cardiovascular disease: collaborative analysis of 58 prospective studies. Lancet 2011;377:1085-95.

15 Global Burden of Metabolic Risk Factors for Chronic Diseases Collaboration (BMI Mediated Effects), Lu Y, Hajifathalian K, et al. Metabolic mediators of the effects of body-mass index, overweight, and obesity on coronary heart disease and stroke: a pooled analysis of 97 prospective cohorts with 1.8 million participants. Lancet 2014;383:970-83.

16 Renehan AG, Tyson M, Egger M, et al. Body-Mass index and incidence of cancer: a systematic review and meta-analysis of prospective observational studies. Lancet 2008;371:569-78.

17 Bhimjiyani A, Knuchel-Takano A, Hunt D, et al. Tipping the scales: why preventing obesity makes economic sense. technical report 2016. Available: https://www.cancerresearchuk.org/sites/default/files/tipping the scales - cruk full report11.pdf [Accessed 26 Jan 2020].

18 Wang YC, McPherson K, Marsh T, et al. Health and economic burden of the projected obesity trends in the USA and the UK. Lancet 2011;378:815-25.

19 Lee M. Half of the socioeconomic costs of obesity are 'medical costs'. Korea Biomedical Review, 2018. Available: http://www. docdocdoc.co.kr/news/articleView.html?idxno=1063317/ [Accessed 29 Jan 2020].

20 Low S, Chin MC, Ma S, et al. Rationale for redefining obesity in Asians. Ann Acad Med Singap 2009;38:66-9.

21 The World Health Organization Western Pacific Region, International Association for the Study of Obesity. The Asia-Pacific perspective: redefining obesity and its treatment. Sydney, Australia: Health Communications Australia Pty Limited, 2000.

22 Seo MH, Kim Y-H, Han K, et al. Prevalence of Obesity and Incidence of Obesity-Related Comorbidities in Koreans Based on National Health Insurance Service Health Checkup Data 2006-2015 (J Obes Metab Syndr 2018;27:46-52). J Obes Metab Syndr 2018;27:198-9.

23 Seo MH, Lee WY, Kim SS, et al. Korean Society for the study of obesity guideline for the management of obesity in Korea. J Obes Metab Syndr 2018;2019:40-5.

$24 \mathrm{Kim}$ D. Estimation of disease and disease burden by health behavior Sejong City: Korea Institute for Health and Social Affairs, 2018.

25 Çağlayan Çağlar, Terawaki H, Chen Q, et al. Microsimulation modeling in oncology. JCO Clin Cancer Inform 2018;2:1-11.

26 Hennessy D, Garner R, Flanagan W, et al. Development of a population-based microsimulation model of body mass index. Health Rep 2017;28:20-30.

27 Spielauer M. Dynamic microsimulation of health care demand, health care finance and the economic impact of health behaviours: survey and review. International Journal of Microsimulation 2007;1:35-53.

28 The National Academies of Sciences. Engineering, and medicine. assessing prevalence and trends in obesity: Navigating the evidence. Washington DC: The National Academies Press, 2016.

29 Soyiri IN, Reidpath DD. An overview of health forecasting. Environ Health Prev Med 2013;18:1-9.

30 Pineda E, Sanchez-Romero LM, Brown M, et al. Forecasting future trends in obesity across Europe: the value of improving surveillance. Obes Facts 2018;11:360-71.

31 Zucchelli E, Jones AM, Rice N. The evaluation of health policies through dynamic microsimulation methods. International Journal of Microsimulation 2012;5:2-20.

32 Hennessy DA, Flanagan WM, Tanuseputro $\mathrm{P}$, et al. The population health model (POHEM): an overview of rationale, methods and applications. Popul Health Metr 2015;13:24.

33 Manuel DG, Tuna M, Hennessy D, et al. Projections of preventable risks for cardiovascular disease in Canada to 2021: a microsimulation modelling approach. CMAJ Open 2014;2:E94-101.

34 Korea health panel study. Available: https://www.khp.re.kr:444/eng/ main.do [Accessed 30 Nov 2020].

35 KOrean Statistical Information Service. Available: https://kosis.kr/ eng/ [Accessed 30 Nov 2020].

36 Korea National health and nutrition examination survey. Available: https:// knhanes.cdc.go.kr/knhanes/eng/index.do [Accessed 30 Nov 2020].

37 Lin J, Thompson TJ, Cheng YJ, et al. Projection of the future diabetes burden in the United States through 2060. Popul Health Metr 2018;16:9.

38 Luhar S, Timæus IM, Jones R, et al. Forecasting the prevalence of overweight and obesity in India to 2040. PLoS One 2020;15:e0229438

39 Finkelstein EA, Khavjou OA, Thompson $\mathrm{H}$, et al. Obesity and severe obesity forecasts through 2030. Am J Prev Med 2012;42:563-70. 
40 Haby MM, Markwick A, Peeters A, et al. Future predictions of body mass index and overweight prevalence in Australia, 2005-2025. Health Promot Int 2012;27:250-60.
41 Ministry of Health and Welfare. National health plan 2020. Available: https://www.mindbank.info/item/4070 [Accessed 26 Nov 2020].

42 Choi JS, Choi SE, Yeom AR, et al. A report on the Korea health panel survey of 2011. Korea Institute for Health and Affairs, 2013. 